\title{
Age- and Sex-Related Differences in Force-Velocity Characteristics of Upper and Lower Limbs of Competitive Adolescent Swimmers
}

\author{
by \\ Pantelis Theo Nikolaidis ${ }^{1}$
}

While there is a direct relationship between maximal anaerobic power (Pmax) and swimming performance, the relationship between upper and lower limbs with regard to Pmax and force-velocity (F-v) characteristics is not clear. The aim of the present study was to examine the effect of age and sex on the ratios of mechanical characteristics between upper and lower extremities of adolescent swimmers. Seventeen girls (aged 14.7 $\pm 1.8 \mathrm{yr}$ ) (mean \pm standard deviation) and 28 boys $(14.6 \pm 1.4 \mathrm{yr}$ ), all members of competitive swimming clubs, performed a F-v test for both legs and arms. In legs, boys had higher values of Pmax ( $\left.t_{43}=2.4, p<0.05\right)$, Pmax expressed in relative to body mass values ( $\left.r P m a x, t_{43}=3.4, p<0.01\right)$ and $v_{0}\left(t_{43}=4.3, p<0.001\right)$, while no differences were found for $F_{0}\left(t_{43}=1.0, p=0.31\right)$ and $v_{0} / F_{0}\left(t_{43}=0.55, p=0.59\right)$. In arms, boys had higher values of $P \max \left(t_{43}=3.2, p<0.01\right), r P \max \left(t_{43}=3.9, p<0.001\right)$ and $v_{0}\left(t_{43}=3.4\right.$, $p<0.01)$, while no differences were found for $F_{0}\left(t_{43}=1.9, p=0.06\right)$ and $v_{0} / F_{0}\left(t_{43}=0.16, p=0.87\right)$. However, no sex difference was found with regard to the ratios of Pmax $\left(t_{33}=1.9, p=0.06\right), F_{0}\left(t_{43}=1.2, p=0.23\right)$ and $v_{0}\left(t_{43}=1.3, p=0.20\right)$ between upper and lower extremities. There was direct relationship between age and Pmax of legs $(r=0.64, p<0.01$ in girls; $r=0.43, p<0.05$ in boys) and arms $(r=0.56, p<0.05 ; r=0.57$, $p<0.01$ respectively), while there was not any significant association between age and the ratios of mechanical characteristics of upper and lower limbs. These findings emphasize the need for separate evaluation of arms' and legs' force-velocity characteristics on a regular basis and the consideration of these measures in training design.

Key words: arms, legs, power output, speed, strength.

\section{Introduction}

Performance in swimming depends on physiological and psychological characteristics of athletes. These characteristics in adolescent athletes are under the influence of growth and maturation and consequently they may be differed from those of their adult counterparts. Young swimmers do not differ only from their adult counterparts, but also from athletes of other sport disciplines; e.g. compared with tennis, figure skating and volleyball players, adolescent female swimmers have unique physiological characteristics of aerobic power, muscular endurance and flexibility (Leone et al., 2002). Compared with badminton players, archers and nonathletes, swimmers exchibit better muscle symmetry and increased symmetry of autonomic indices (Balashova et al., 2004). In addition, adolescent swimmers have more stable circulatory system than those, who are not engaged in sports (Luchitskaya and Rusanov, 2009), and they have lower heart rate at rest than basketball players and other athletes (Vanyushin and Sitdikov, 2001).

With regard to bioenergetics, all swimmers do not have a unique profile and the relative contribution of each metabolic pathway (ATP-CP, lactic anaerobic, aerobic) depends on swimming distance (Volkov et al., 2005). Hawley and Williams (1991) noted that time in swimming over $50 \mathrm{~m}$ was correlated with anaerobic power of arms. Subsequent investigators have shown that performance in $50 \mathrm{~m}$ was associated with anaerobic power of legs (Duché et al., 1993) and that performance in 25-100 $\mathrm{m}$ was correlated with both upper and lower limbs' anaerobic power (Strzala and Tyka, 2009). While there are the abovementioned reports of significant

1. Laboratory of Human Performance and Rehabilitation, Division of Physical and Cultural Education, Hellenic Army Academy, Athens, Greece..

Authors submitted their contribution of the article to the editorial board.

Accepted for printing in Journal of Human Kinetics vol. 32/2012 on May 2012. 
Equipment and protocols. Height and body mass were measured using a stadiometer (SECA, Leicester, UK) and an electronic scale (HD-351, Tanita, Illinois, USA), respectively. Percentage of body fat was calculated from the sum of 10 skinfolds using a skinfold calliper (Harpenden, West Sussex, UK), based on the formula proposed by Parizkova (1978). The employment of skinfolds as a method of body fat estimation was validated in a sample of 12-18 yr swimmers, where the correlation between skinfold thickness and dual-energy X-ray outcome was 0.98 (Tuuri and Loftin, 1999).

The F-v test was used to assess Pmax, vo and Fo, and it employed various applied braking forces that elicited different pedalling velocities in order to derive Pmax (Vandewalle et al., 1985). The warm-up activity, which was conducted before the test, included stretching exercises, steady-paced cycling, and short submaximal sprints. Minimal warming-up and learning experience was necessary in order to perform a true maximal sprint. The participants performed four supramaximal pedal sprints, each lasting $7 \mathrm{sec}$, against incremental braking force, on a cycle ergometer (Ergomedics 874, Monark, Sweden). During each sprint, participants were encouraged to reach their maximal velocity as soon as possible. Seat height was adjusted to each participant's satisfaction, and toe clips with straps were used to prevent the feet from slipping off the pedals. The participants performed five supramaximal pedal sprints, each lasting $7 \mathrm{sec}$, against incremental braking force, on an arm-cranking and cycle ergometer (Ergomedics 874, Monark, Sweden).

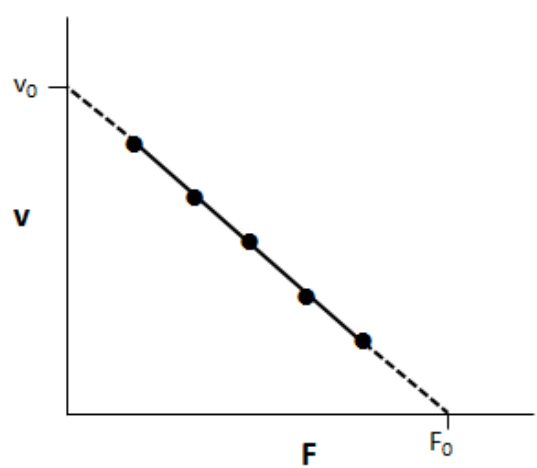

Figure 1

The inverse linear relationship between braking force

$(F)$ and velocity (v), and their corresponding theoretical maximal values (Fo and vo)

The test began with a braking force of $30 \mathrm{~N}$ for legs and $20 \mathrm{~N}$ for arms. In every subsequent sprint, $10 \mathrm{~N}$ was added. During each sprint, participants were encouraged to reach their maximal velocity as soon as possible. This value of peak velocity was recorded and used to calculate F-v relationship (Figure 1).

The recovery period between each exercise bout was 5 minutes. Sprints were performed for legs and arms alternately. The F-v test was suggested to be reliable measure of short-term power output of children, adolescents and adults tested twice within a week (testretest coefficient of variation 3\% (Doré et al., 2003)). With regard to its validity, this test was highly correlated with the Wingate anaerobic test (Vandewalle et al., 1987).

Data and statistical analysis. For each participant, an individual linear regression (least squares method) was determined between peak pedalling frequency and breaking force for each of the five sprints (five data points for each F-v relationship). The $F_{0}$ and vo corresponded to the intercepts with the force and velocity axes in the F-v graph. At both of these locations, power is equal to zero. Because both velocity and force are nonzero between these endpoints, power varied with a bell-shaped profile depending on the magnitude of the product (Enoka, 1994). Pmax was determined at an optimal force and optimal velocity of $0.5 \mathrm{~F}_{0}$ and $0.5 \mathrm{v} 0$ and was calculated as Pmax $=0.25 \cdot F_{0} \cdot$ vo. The comparison for each measured parameter between upper and lower limbs was calculated by the equation $x=\frac{y}{z}$, where $\mathrm{x}$ was the result of comparison, $\mathrm{y}$ the upper limbs' mean value and $\mathrm{z}$ the corresponding mean value of lower limbs. The duration of every flywheel revolution was measured with the help of electronic sensor and power output of every revolution was computed by specialized software.

All data are presented as means \pm standard deviations. The Pearson product moment coefficient of correlation $(r)$ was used to examine the association between upper and lower limbs with regard to F-v characteristics, as well as the relationship between age and these characteristics. The dependent one-tailed Student $t$-test was used to determine whether upper and lower limbs mechanical characteristics' means differed from each other, and the independent $t$-test to examine sex differences. Statistical analyses were performed using IBM SPSS v.20.0 statistical software (SPSS Inc., Chicago, IL, USA). Significance was set at alpha $=0.05$ for all the tests. 


\section{Results}

The force-velocity characteristics of upper and lower limbs of participants are presented in Table 2. In girls, arms and legs differed with regard to Pmax $\left(t_{16}=14.4, p<0.001\right), \operatorname{rPmax}\left(t_{16}=19.8, p<0.001\right), \mathrm{F}_{0}\left(t_{16}=15.3\right.$, $p<0.001)$, $\mathrm{v}_{0}\left(t_{16}=47.5, p<0.001\right)$ and $\mathrm{v}_{0} / \mathrm{F}_{0}\left(\mathrm{t}_{16}=14.2, p<0.001\right)$. In boys, upper and lower extremities differed with respect to $P \max \left(t_{22}=17.8, p<0.001\right), \mathrm{rP}_{\max } \quad\left(t_{2}=31.5\right.$, $p<0.001), \mathrm{F}_{0}\left(t_{2}=19.8, p<0.001\right)$, $\mathrm{v}_{0}\left(t_{22}=48.8, p<0.001\right)$ and $\mathrm{V}_{0} / \mathrm{F}_{0}\left(t_{2}=20.1, p<0.001\right)$. All participants had lower values in arms than in legs, except of $\mathrm{v}_{0} / \mathrm{F}_{0}$.

In both upper and lower limbs comparable sex differences were found. In legs, boys had higher values of Pmax $\left(t_{43}=2.4, p<0.05\right)$, rPmax $\left(t_{33}=3.4, p<0.01\right)$ and $v_{0}$ $\left(\mathrm{t}_{4}=4.3, p<0.001\right)$, while no differences were found for $\mathrm{F}_{0}$ $\left(t_{43}=1, p=0.31\right)$ and $\mathrm{v}_{0} / \mathrm{F}_{0}\left(t_{43}=0.55, p=0.59\right)$.

Table 2

\begin{tabular}{|c|c|c|c|}
\hline & & Girls & Boys \\
\hline \multirow[t]{5}{*}{ Lower limbs } & $\operatorname{Pmax}(W)$ & $565 \pm 162$ & $709 \pm 210^{*}$ \\
\hline & $\operatorname{rPmax}\left(\mathrm{W} \cdot \mathrm{kg}^{-1}\right)$ & $10.0 \pm 2.1$ & $12.2+2.0+$ \\
\hline & V0 (rpm) & $166 \pm 14$ & $191+21 \ddagger$ \\
\hline & $\mathrm{F}_{0}(\mathrm{~N})$ & $136 \pm 37$ & $148 \pm 40$ \\
\hline & $\mathrm{v}_{0} / \mathrm{F}_{0}\left(\mathrm{rpm} \mathrm{N}^{-1}\right)$ & $1.31 \pm 0.38$ & $1.37 \pm 0.36$ \\
\hline \multirow[t]{5}{*}{ Upper limbs } & $\operatorname{Pmax}(W)$ & $188 \pm 76$ & $272+90+$ \\
\hline & $\operatorname{rPmax}\left(\mathrm{W} \cdot \mathrm{kg}^{-1}\right)$ & $3.3 \pm 1.1$ & $4.7 \pm 1.0 \ddagger$ \\
\hline & Vo (rpm) & $125 \pm 18$ & $153 \pm 32+$ \\
\hline & $\mathrm{F}_{0}(\mathrm{~N})$ & $59 \pm 20$ & $72+22$ \\
\hline & $\mathrm{v}_{0} / \mathrm{F}_{0}\left(\mathrm{rpm} \cdot \mathrm{N}^{-1}\right)$ & $2.31 \pm .78$ & $2.36 \pm .97$ \\
\hline Upper to & Pmax & $0.34 \pm 0.09$ & $0.40 \pm 0.11$ \\
\hline lower limbs & $\mathrm{F}_{0}$ & $0.45 \pm 0.14$ & $0.50 \pm 0.15$ \\
\hline ratio & $\mathrm{V}_{0}$ & $0.76 \pm 0.09$ & $0.80 \pm 0.13$ \\
\hline
\end{tabular}

${ }^{*} p<0.05,+p<0.01, \pm p<0.001$ (Student's t test) denote differences between the two groups

Table 3

Correlation coefficient $r$ between age and the force-velocity characteristics of participants

\begin{tabular}{|c|c|c|c|}
\hline & & Girls & Boys \\
\hline \multirow{5}{*}{$\begin{array}{l}\text { Lower } \\
\text { limbs }\end{array}$} & $\operatorname{Pmax}(W)$ & $0.64 \dagger$ & $0.43^{*}$ \\
\hline & $\operatorname{rPmax}\left(\mathrm{W} \cdot \mathrm{kg}^{-1}\right)$ & 0.23 & 0.14 \\
\hline & V0 (rpm) & 0.19 & $0.56+$ \\
\hline & $\mathrm{F}_{0}(\mathrm{~N})$ & $0.60^{*}$ & 0.26 \\
\hline & $\mathrm{v} 0 / \mathrm{F}_{0}\left(\mathrm{rpm} \mathrm{N}^{-1}\right)$ & $-0.47(P=0.06)$ & -0.09 \\
\hline \multirow{5}{*}{$\begin{array}{l}\text { Upper } \\
\text { limbs }\end{array}$} & $\operatorname{Pmax}(\mathrm{W})$ & $0.56^{*}$ & $0.57 \dagger$ \\
\hline & $\operatorname{rPmax}\left(\mathrm{W} \cdot \mathrm{kg}^{-1}\right)$ & 0.16 & $0.37(P=0.05)$ \\
\hline & V0 (rpm) & 0.34 & $0.37(P=0.06)$ \\
\hline & $\mathrm{F}_{0}(\mathrm{~N})$ & $0.47(P=0.06)$ & $0.37(P=0.05)$ \\
\hline & $\mathrm{v}_{0} / \mathrm{F}_{0}\left(\mathrm{rpm} \mathrm{N}^{-1}\right)$ & -0.30 & -0.08 \\
\hline \multirow{3}{*}{$\begin{array}{l}\text { Upper to } \\
\text { lower limbs } \\
\text { ratio }\end{array}$} & Pmax & 0.06 & 0.23 \\
\hline & $\mathrm{F}_{0}$ & -0.08 & 0.14 \\
\hline & $\mathrm{V}_{0}$ & 0.26 & 0.10 \\
\hline
\end{tabular}



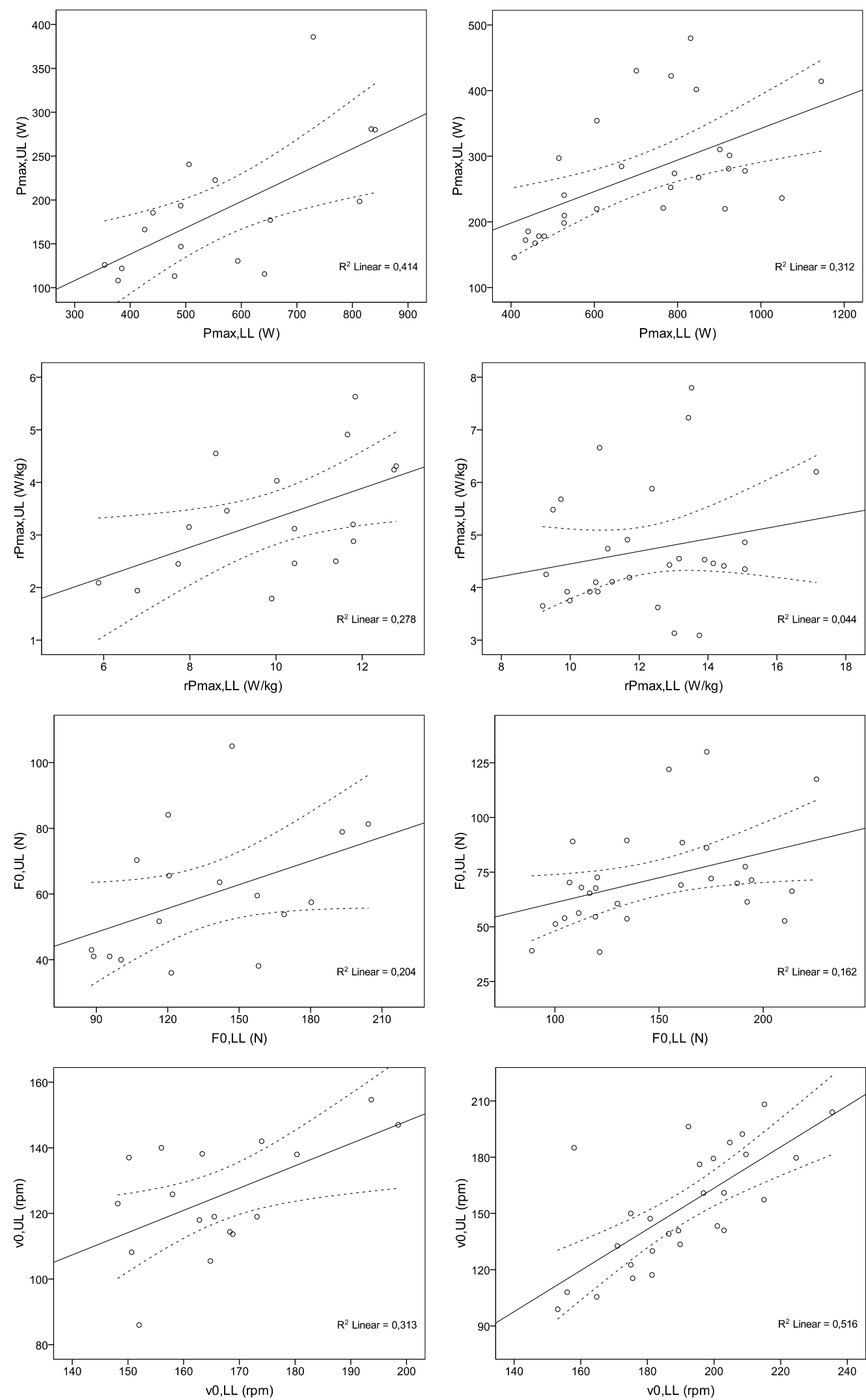

Figure 2

Relationship between upper and lower limbs' mechanical characteristics in girls (left) and in boys (right). Dashed lines represent $95 \%$ confidence intervals of means 
In arms, boys had higher values of $\operatorname{Pmax}\left(t_{43}=3.2, p<0.01\right)$, rPmax $\left(t_{43}=3.9, p<0.001\right)$ and $v_{0}\left(t_{43}=3.4, p<0.01\right)$, while no differences were found for $\mathrm{F}_{0}\left(t_{43}=1.9, p=0.06\right)$ and $\mathrm{v}_{0} / \mathrm{F}_{0}$ $\left(t_{43}=0.16, p=0.87\right)$. In addition, no sex difference was found with regard to the ratios of $P \max \left(t_{43}=1.9, p=0.06\right)$, $\mathrm{F}_{0}\left(t_{43}=1.2, p=0.23\right)$ and $\mathrm{v}_{0}\left(t_{43}=1.3, p=0.20\right)$ between upper and lower extremities.

The mechanical characteristics of lower limbs were in association with the corresponding of upper limbs. In girls, these associations, with the exception of $\mathrm{F}_{0}$, were statistically significant; $r=0.64(p<0.01)$ in Pmax, $r=0.53$ $(p<0.05)$ in rPmax, $r=0.45(p=0.069)$ in $F_{0}$ and $r=0.56$ $(p<0.05)$ in vo. In boys, these associations, with the exception of rPmax, were also statistically significant; $r=0.56(p<0.05)$ in Pmax, $r=0.21$ (n.s.) in rPmax, $r=0.40$ $(p<0.05)$ in $\mathrm{F}_{0}$ and $r=0.72(p<0.001)$ in $\mathrm{v}_{0}$ (Figure 2$)$.

As shown in Table 3, $P_{\max }$ was in direct relationship with age for both sexes and for both upper and lower limbs. Regarding the rest parameters of F-v relationship, there was no consistency in their association with age.

\section{Discussion}

Although it is clearly recognized that anaerobic power is linked with performance in swimming, little is known about the F-v characteristics of those who practise this sport. This is the first study to examine the relationship between upper and lower limbs' F-v relationship in swimmers. We demonstrated that Pmax, rPmax, $F_{0}, \quad v_{0}$ and $v_{0} / F_{0}$ differed significantly between arms and legs. Pmax, rPmax, Fo and vo were higher in legs, while $\mathrm{v}_{0} / \mathrm{F}_{0}$ was higher in arms, i.e. arms had a more "fast" profile and legs a more "strong" profile. These observations were noted in both sexes. With a few exceptions ( $\mathrm{F}_{0}$ in girls and rPmax in boys), we observed direct relationships between upper and lower extremities' mechanical characteristics, i.e. the higher the value of legs, the higher the value of arms, and vice versa. In girls, Pmax of legs accounted for by $41 \%$ of the variance in Pmax in arms and in boys, the respective value was $31 \%$.

With regard to sex-related differences, either in upper or in lower extremities, boys had higher values of Pmax, rPmax and vo than girls, while no differences were found for $\mathrm{F}_{0}$ and $\mathrm{v}_{0} / \mathrm{F}_{0}$. Previous studies had identified the higher power in boys. For instance, arm muscle power, assessed by Wingate anaerobic test, was higher in male swimmers than females (Ogonowska et al., 2009), while leg muscle power, assessed by various vertical jumps, was also higher in elite male swimmers than their female counterparts (Buśko and Gajewski, 2011). Age was in direct relationship with Pmax, but the association with the other measures of F-v parameters was not statistically significant. Our results were scrutinized together with relevant data of other researchers, who used similar methods. The positive relationship between age and Pmax came to terms with previous findings (Duché et al., 1993; Prioux et al., 2001; Vandewalle et al., 1989). Elite French male swimmers had upper limbs' Pmax 286

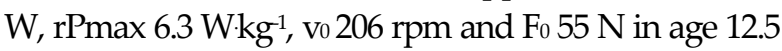
$\mathrm{yr}$, which were lower than the corresponding values of their 17.5 yr counterparts: $718 \mathrm{~W}, 10.1 \mathrm{~W} \mathrm{~kg}^{-1}, 254 \mathrm{rpm}$ and $112 \mathrm{~N}(n=28)$ (Vandewalle et al., 1989). In another study on French male swimmers' arms, aged 15.2 yr, vo was 222 rpm, Fo 100 N, Pmax 565 W, rPmax 8.9 W $k^{-1}$ and $\mathrm{v}_{0} / \mathrm{F}_{0} 2.45 \mathrm{rpmN}^{-1}$ (Prioux et al., 2001). In French male swimmers' lower extremities, aged 11.3 yr, Pmax was $565 \mathrm{~W}$ and rPmax $8.9 \mathrm{~W}^{\mathrm{kg}}{ }^{-1}$ (Duché et al., 1993).

$\mathrm{F}_{0}, 72 \mathrm{~N}$ and $148 \mathrm{~N}$, of upper and lower limbs in boys respectively, is lower than the corresponding values in male students $(140 \mathrm{~N}$ and $223 \mathrm{~N}$ (Nikolaidis, 2006)) and in active male adults (values only for lower extremities; $112 \mathrm{~N}$ (Vandewalle et al., 1985); $198 \mathrm{~N}$ (Chamari et al., 1995)). Vo, $153 \mathrm{rpm}$ and $191 \mathrm{rpm}$, of upper and lower extremities in boys accordingly, is also lower than previous findings for upper limbs (229 rpm in male students (Nikolaidis, 2006)) as well as for lower limbs (211 rpm in male students (Nikolaidis, 2006); 216 rpm in young endurance athletes ((Chamari et al., 1995); $228 \mathrm{rpm}$ in recreationally active men (Vandewalle et al., 1985)).

The result of Pmax for upper limbs (272 W) is lower than the reference data (790 W (Nikolaidis, 2006), $884 \mathrm{~W}$ for $44 \mathrm{yr}$ and $960 \mathrm{~W}$ for physical education students (Adach et al., 1999)). The corresponding values for lower limbs $(708 \mathrm{~W})$ is also lower than other reported data (1211 W (Nikolaidis, 2006), $1180 \mathrm{~W}$ in students (Jaskolska et al., 1999); $1114 \mathrm{~W}$ in $44 \mathrm{yr} ; 1029 \mathrm{~W}$ in physical education students (Adach et al., 1999); $1090 \mathrm{~W}$ in young endurance athletes (Chamari et al., 1995), 813 $\mathrm{W}$ in subjects with recreational activities (Vandewalle et al., 1985); $879 \mathrm{~W}$ in untrained students (Linossier et al., 1996)). The measured with the F-v test rPmax for upper limbs is $4.7 \mathrm{~W} \cdot \mathrm{kg}^{-1}$, while other studies reveal higher values (10.7 W:kg-1 (Nikolaidis, 2006); $10.7 \mathrm{~W} \cdot \mathrm{kg}^{-1}$ in 44 year-olds and $12.3 \mathrm{~W} \mathrm{~kg}^{-1}$ in physical education students (Adach et al., 1999); $10.7 \mathrm{~W} \mathrm{~kg}^{-1}$ in swimmers (Mercier et al., 1993)). The corresponding value for lower limbs (12.2 $\left.\mathrm{W} \cdot \mathrm{kg}^{-1}\right)$ is lower than previous reports; $16.4 \mathrm{~W} \cdot \mathrm{kg}^{-1}$ 
(Nikolaidis, 2006); $13.0 \mathrm{~W} \cdot \mathrm{kg}^{-1}$ in untrained students (Linossier et al., 1996); $13.2 \mathrm{~W} \cdot \mathrm{kg}^{-1}$ in physical education students, $13.7 \mathrm{~W} \cdot \mathrm{kg}^{-1}$ in 44 year-olds (Adach et al., 1999).

The ratio upper to lower limbs Pmax (0.40) is lower than the 0.65 (Nikolaidis, 2006), 0.78 in 44 year-olds and the 0.93 in physical education students (Adach et al., 1999). Two possible explanations for the discrepancy of our results in comparison with previous data (lower values in all the F-v characteristics) might be the age of participants and the sport. All the characteristics measured by F-v test (force, velocity and power) correspond to age-dependent sport-related fitness parameters (muscular strength, speed and anaerobic power).

Potential differences between arms and legs could be explained primarily due to muscle mass and muscle fibre type distribution. Muscle strength or force generating capacity is found closely related to muscle mass (Lanza et al., 2003; Metter et al., 2004) and muscle cross-sectional area (Maugha et al., 1984). It is proposed that upper limbs muscle mass is $22 \%$ (Abe et al., 2003) to $25 \%$ of lower limbs (Zatsiorsky, 2002). Our data additionally suggest that other factors, e.g. sport discipline in swimming, training, individualized technique and injuries, might also influence these differences. As shown in the Figure 2, there was a case of three female swimmers who had similar force in legs $(120 \mathrm{~N}, 121 \mathrm{~N}$ and $122 \mathrm{~N})$, but their corresponding force in arms differed $(84 \mathrm{~N}, 66 \mathrm{~N}$ and $36 \mathrm{~N})$ resulting in a wide range of ratio between upper and lower limbs (0.70, 0.54 and 0.30).

A drawback of our study was the inherent limitation of laboratory methods to reproduce the real movements of swimming. In addition, arms and legs' power output was examined separately, which did not correspond to the complex movements of the sport that involve the coordination of upper and lower limbs. On the other hand, the laboratory methods provided valid and reliable measures of anaerobic power. Moreover, the distinction between arms and legs' power came to terms with the training practice, in which many exercises, either in pool or in the gym, focus on specific body parts. A remarkable observation from the present study was the variability of the ratios of mechanical characteristics between arms and legs in swimmers. Based on these findings, it is recommended to monitor these characteristics regularly and to consider them in the training design.

This study attempted to quantify the proportionality of mechanical characteristics between swimmers' limbs. The results confirmed previous observations that upper limbs had lower values of mechanical characteristics with respect to upper limbs. However, what is novel, is the quantification of these differences in the same participants, young competitive swimmers, which could have practical implications in aspects of their sport training. Further research in this topic should examine the association between swimming performance and the upper to lower limbs' ratio in power output and F-v characteristics, in order to answer the question if there is any optimal ratio.

\section{Conclusions}

This study was the first one to focus on differences of force-velocity characteristics between upper and lower limbs in competitive adolescent swimmers. In summary, we attempted to quantify the proportionality of mechanical characteristics (power, force and velocity) between swimmers' upper and lower extremities. The results confirmed previous observations in general population that arms had lower values of power and force with respect to legs, and smaller differences concerning velocity. Our findings emphasize the need for separate evaluation of arms' and legs' force-velocity characteristics on a regular basis and the consideration of these measures in training design.

\section{Acknowledgments}

We would like to thank all participants who volunteered for this study.

\section{References}

Abe T, Kearn CF, Fukunaga T. Sex differences in whole body skeletal muscle mass measured by magnetic resonance imaging and its distribution in young Japanese adults. Br J Sports Med, 2003; 37: 436-440.

Adach Z, Jaskolska A, Jaskolski A. Influence of age tested men on anaerobic-phosphagenic performance and its components, during arm's and leg's work. Wychowanie Fizyczne I Sport, 1999; 43: 37-45.

Ayalon A, Inbar O, Bar-Or O. Relationships among measurements of explosive strength and anaerobic power. In Nelson RC, Morehouse CA (Eds.), International Series on Sport Science 1: Biomechanics IV (pp. 527-532). Baltimore: University 
Park Press, 1974.

Balashova ER, Pleshchinskii IN, Eremeev AM. Motor and autonomic asymmetries in athletes with different specializations. Hum Physiol, 2004; 30(5): 591-595.

Bosco C, Luhtanen P, Komi PV. A simple method for measurement of mechanical power in jumping. Eur J Appl Physiol Occup Physiol, 1983; 50: 273-282.

Buśko K, Gajewski J. Muscle Strength and Power of Elite Female and Male Swimmers. Baltic Journal of Health and Physical Activity, 2011;3(1): 13-18.

Chamari K, Ahmaidi S, Fabre C, Masse-Biron J, Prefaut C. Anaerobic and aerobic peak power output and the forcevelocity relationship in endurance-trained athletes: effects of aging. Eur J Appl Physiol Occup Physiol, 1995; 71: 230234 .

Davis JA, Vodak P, Wilmore JH, Vodak J, Kurtz P. Anaerobic threshold and maximal aerobic power for three modes of exercise. J Appl Physiol, 1976; 41(4): 544-550.

Doré E, Duché P, Rouffet D, Ratel S, Bedu M, Van Praagh E. Measurement error in short-term power testing in young people. J Sports Sci, 2003; 21:134-142.

Duché P, Falgairette G, Bedu M, Lac G, Robert A, Coudert J. Analysis of performance of prepubertal swimmers assessed from anthropometric and bio-energetic characteristics. Eur J Appl Physiol Occup Physiol, 1993; 66: 467-471.

Enoka RM. Neuromechanical Basis of Kinesiology. Champaign: Human Kinetics, 1994.

Giovani D, Nikolaidis PT. Differences in Force-velocity Characteristics of Upper and Lower Limbs of Non-competitive Male Boxers. Int J Exerc Sci, 2012; 5(2): 106-113.

Hawley JA, Williams MM. Relationship between upper body anaerobic power and freestyle swimming performance. Int J Sports Med, 1991; 12: 1-5.

Jaskolska A, Goossens P, Veenstra B, Jaskolski A, Skinner JS. Comparison of treadmill and cycle ergometer measurements of force-velocity relationships and power output. Int J Sports Med, 1999; 20: 192-197.

Kang JIE, Robertson RJ, Goss FL, Dasilva SG, Suminski RR, Utter AC, Zoeller RF, Metz KF. Metabolic efficiency during arm and leg exercise at the same relative intensities. Med Sci Sport Exerc, 1997; 29(3): 377-382.

Koppo K, Bouckaert J, Jones AM. Oxygen uptake kinetics during high-intensity arm and leg exercise. Respir Physiol Neurobiol, 2002; 133(3): 241-250.

Lanza IR, Towse TF, Caldwell GE, Wigmore DM, Kent-Braun JA. Effects of age on human muscle torque, velocity and power in two muscle groups. J Appl Physiol, 2003; 95: 2361-2369.

Leone M, Lariviere G, Comtois, AS. Discriminant analysis of anthropometric and biomotor variables among elite adolescent female athletes in four sports. J Sports Sci, 2002; 20(6): 443-449.

Linossier MT, Dormois D, Fouquet R, Geyssant A, Denis C. Use of the force-velocity test to determine the optimal braking force for a sprint exercise on a friction-loaded cycle ergometer. Eur J Appl Physiol Occup Physiol, 1996; 74: 420-427.

Luchitskaya ES, Rusanov VB. Functional characteristics of hemodynamics in adolescents under the conditions of different motor activities. Hum Physiol, 2009; 35(4): 43-50.

Maughan RJ, Watson JS, Weir J. Muscle strength and cross-sectional area in man: a comparison of strength-trained and untrained subjects. Br J Sports Med, 1984; 18: 149-157.

Mercier B, Granier P, Mercier J, Trouquet J, Prefaut C. Anaerobic and aerobic components during arm-crank exercise in sprint and middle-distance swimmers. Eur J Appl Physiol Occup Physiol, 1993; 66: 461-466.

Metter EJ, Talbot LA, Schrager M, Conwit RA. Arm-cranking muscle power and arm isometric muscle strength are independent predictors of all-cause mortality in men. J Am Physiol, 2004; 96: 814-821.

Nikolaidis P. Differences in force-velocity characteristics between upper and lower limbs of male students. Acta Universitatis Carolinae Kinanthropologica, 2006; 42(1): 63-74.

Nikolaidis PT, Fragkiadakis G, Papadopoulos VE, Karydis NV. Differences in force-velocity characteristics of upper and lower limbs of male kickboxers. Baltic Journal of Health and Physical Activity, 2011; 3(3): 147-153. 
Ogonowska A, Hübner-Woźniak E, Kosmol A, Gromisz W. Anaerobic capacity of upper extremity muscles of male and female swimmers. Biomed Hum Kinetics, 2009; 1:79-82.

Parizkova J. Lean body mass and depot fat during autogenesis in humans. In Parizkova J, Rogozkin V (Ed.), Nutrition, Physical Fitness and Health: International Series on Sport Sciences. Baltimore: University Park Press, 1978.

Prioux J, Ayoub J, Houel N, Berger M, Ramonatxo M, Prefaut C. Effect of training on aerobic and anaerobic capacity in young swimmers: exercise performed with arms. Science \& Sports, 2001; 16, 306-314.

Strzala M, Tyka A. Physical endurance, somatic indices and swimming technique parameters as determinants of front crawl swimming speed at short distances in young swimmers. Medicina Sportiva, 2009; 13(2): 99-107.

Tuuri G, Loftin JM. Comparison and relationship of body composition methods in swimmers aged 12 to 18. J Am Dietetic Assoc, 1999; 99(9): A87.

Vandewalle H, Heller J, Peres G, Raveneau S, Monod H. Etude comparative entre le Wingate test et un test force-vitesse sur ergocycle. Science \& Sports, 1987; 2(4): 279-284.

Vandewalle H, Peres G, Heller J, Monod H. All out anaerobic capacity tests on cycle ergometers, a comparative study on men and women. Eur J Appl Physiol Occup Physiol, 1985; 54: 222-229.

Vandewalle H, Peres G, Sourabie B, Stouvenel O, Monod H. Force-velocity characteristics and maximal anaerobic power during cranking exercise in young swimmers. Int J Sports Med, 1989; 10: 439-445.

Vanyushin YS, Sitdikov FG. Adaptation of cardiac performance to physical exercise of increasing power in adolescents. Hum Physiol, 2001; 27(2): 210-215.

Vokac Z, Bell H, Bautz-Holter E, Rodahl K. Oxygen uptake/heart rate relationship in leg and arm exercise, sitting and standing. J Appl Physiol, 1975; 39(1): 54-59.

Volkov NI, Popov OI, Gabrys T, Shmatlyan-Gabrys U. Physiological criteria in defining the standards for training and competition loads in elite sports. Hum Physiol, 2005; (31): 606-614.

Zatsiorsky VM. Kinetics of Human Motion. Champaign: Human Kinetics, 2002.

\section{Corresponding author:}

\section{Pantelis Theo Nikolaidis, Ph.D;}

Laboratory of Human Performance and Rehabilitation, Division of Physical and Cultural Education,

Hellenic Army Academy, Greece; 7 Thermopylon, Nikaia 18450, Athens, Greece

Phone: +306977820298

Fax: +302104907557

E-mail: pademil@hotmail.com 